\title{
Incidence and progression of diabetic retinopathy in Japanese adults with type 2 diabetes: 8 year follow-up study of the Japan Diabetes Complications Study (JDCS)
}

\author{
R Kawasaki - S Tanaka $\cdot$ S Tanaka - T Yamamoto $\cdot H$ Sone $\cdot$ Y Ohashi \\ Y Akanuma • N Yamada • H Yamashita • \\ on behalf of the Japan Diabetes Complications Study Group
}

Received: 18 November 2010 / Accepted: 27 April 2011 /Published online: 1 June 2011

(C) Springer-Verlag 2011

\begin{abstract}
Aims/hypothesis The aim of this study was to determine the incidence and progression rates of diabetic retinopathy and their associations in Japanese individuals with type 2 diabetes.

Methods This is a part of the Japan Diabetic Complications Study (JDCS), a multi-centred randomised trial of type 2 diabetes patients aged 40-70 years with an 8 year followup. There were 1,221 patients without diabetic retinopathy at baseline; incidence of diabetic retinopathy was defined as the development of any diabetic retinopathy. There were 410 patients with mild non-proliferative diabetic retinopathy at baseline; progression of diabetic retinopathy was defined as the development of severe non-proliferative diabetic retinopathy or proliferative diabetic retinopathy.
\end{abstract}

R. Kawasaki $\cdot$ T. Yamamoto $\cdot H$. Yamashita $(\bowtie)$

Department of Ophthalmology, Faculty of Medicine,

Yamagata University,

2-2-2 Iida-Nishi,

Yamagata 990-9585, Japan

e-mail: jdcstudy@md.tsukuba.ac.jp

R. Kawasaki

Centre for Eye Research Australia,

Royal Victorian Eye and Ear Hospital,

Melbourne, Victoria, Australia

R. Kawasaki

Centre for Clinical Research Excellence in Diabetes Research,

St Vincent's Hospital, University of Melbourne,

Melbourne, Victoria, Australia

S. Tanaka

EBM Research Center,

Kyoto University Graduate School of Medicine,

Kyoto, Japan
We used multivariate proportional Cox hazard models, and generalised additive models were also applied to identify potential threshold effect.

Results The incidence and progression rate of diabetic retinopathy was 38.3/1,000 person-years and 21.1/1,000 person-years, respectively. Higher $\mathrm{HbA}_{1 \mathrm{c}}$ (adjusted $\mathrm{HR}$ [aHR] per $1 \%$ [10.9 mmol/mol] 1.36 [95\% CI 1.28-1.45]), longer duration of diabetes (aHR per 5 year period 1.26 [95\% CI 1.17-1.35]), higher systolic blood pressure (aHR per $+10 \mathrm{mmHg} 1.01$ [95\% CI 1.00-1.02]) and higher body mass index (aHR per $1 \mathrm{~kg} / \mathrm{m}^{2} 1.05$ [95\% CI 1.00-1.09]) were associated with incident diabetic retinopathy. The association between $\mathrm{HbA}_{1 \mathrm{c}}$ and incident diabetic retinopathy was linear; the association with duration of diabetes increased rapidly between 5 and 10 years. Higher $\mathrm{HbA}_{1 \mathrm{c}}$

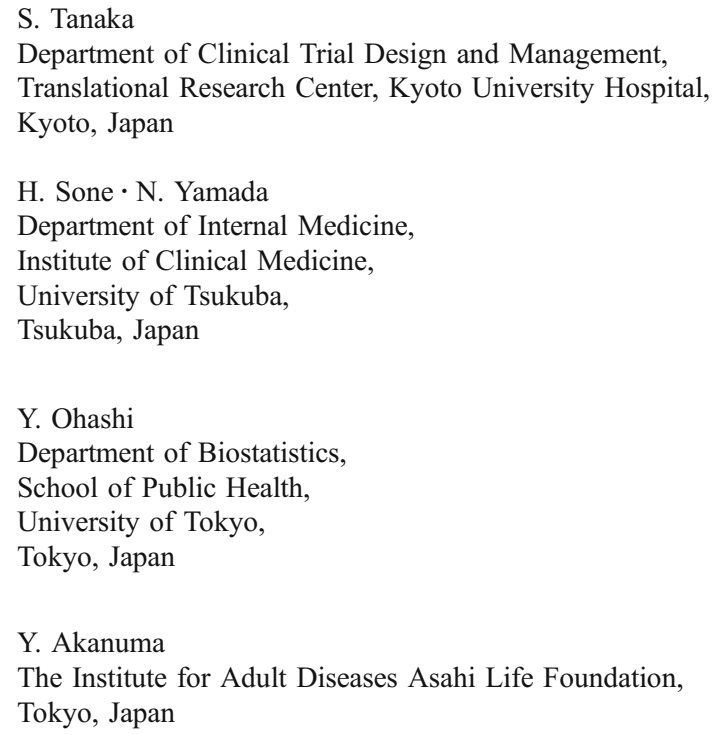


was also associated with progression of diabetic retinopathy (aHR per 1\% [10.9 mmol/mol] 1.66 [95\% CI 1.41-1.96]). Conclusions Observed incidence and progression rates of diabetic retinopathy seemed lower than that in western populations. $\mathrm{HbA}_{1 \mathrm{c}}$ was the only factor associated with both incidence and progression of diabetic retinopathy. The strength of the association between duration of diabetes and incidence of diabetic retinopathy increased rapidly during a period of 5 to 10 years duration of diabetes.

Trial registration: C000000222 (www.umin.ac.jp)

Funding: This study is supported by the Ministry of Health, Labour and Welfare, Japan.

Keywords Diabetic retinopathy $\cdot \mathrm{HbA}_{1 \mathrm{c}} \cdot$ Incidence $\cdot$ Japan Diabetes Complications Study (JDCS) - Type 2 diabetes

\section{Abbreviations}

JDCS Japan Diabetes Complications Study

\section{Introduction}

Diabetic retinopathy is one of the leading causes of blindness in the working-age population [1]. Although improved management of risk factors and advances in treatment modalities for diabetic retinopathy have contributed to reducing the risk of blindness from this pathology [2-4], type 2 diabetes per se has been continuously increasing in Asian populations [5, 6]. The report from the International Diabetes Federation estimated that people with diabetes in the Asian Pacific region will increase from 137 million in 2010 to 214 million by 2030 [7]. Because diabetic retinopathy is one of the common microvascular complications in diabetes, the number of people with diabetic retinopathy is also estimated to increase. Therefore, specific incidence and progression rates of diabetic retinopathy in Asian diabetic patients are necessary to estimate the burden and thus to develop strategic preventive interventions for the management of diabetic retinopathy.

While long-term incidence of diabetic retinopathy is well documented in western populations, such as in the Wisconsin Epidemiologic Study of Diabetic Retinopathy (WESDR) [8], the Fyn Study [9] or in a Hispanic population in the US [10], there has been insufficient information from Asian populations. Those studies reported from Asian countries are either based on relatively small sample sizes or single hospital-based samples [11-14].

With regard to the risk associations for diabetic retinopathy, duration of diabetes and $\mathrm{HbA}_{1 \mathrm{c}}$ are two key risk predictors of diabetic retinopathy; diabetic retinopathy develops in nearly $80 \%$ of those with type 2 diabetes with duration of diabetes of 15 years [15]. However, detailed association between duration of diabetes or $\mathrm{HbA}_{1 \mathrm{c}}$ and incidence or progression of diabetic retinopathy in Asian samples is also not well documented. Okudaira et al. [16] has reported association between duration of diabetes or $\mathrm{HbA}_{1 \mathrm{c}}$ and progression of diabetic retinopathy in Japanese patients with early-onset type 2 diabetes. Shiraiwa et al. has reported that postprandial hyperglycaemia was more influential than fasting glycaemia or $\mathrm{HbA}_{1 \mathrm{c}}$ in the risk of incidence or progression of diabetic retinopathy in Japanese patients with diabetes who were admitted to their hospital [17, 18].

Recently, the American Diabetes Association recommended using $\mathrm{HbA}_{1 \mathrm{c}}$ levels to diagnose diabetes based on the observation that the prevalence of diabetic retinopathy increases rapidly in individuals with $\mathrm{HbA}_{1 \mathrm{c}} \geq 6.5 \%$ (47.5 mmol/mol) [19]. However, whether there is a clear cut-off value in $\mathrm{HbA}_{1 \mathrm{c}}$ associated with rapid increased incidence or progression of diabetic retinopathy is uncertain.

This study aims to determine the incidence and progression rate of diabetic retinopathy in adult Japanese patients with type 2 diabetes, together with their risk associations, with a focus in the duration of diabetes and $\mathrm{HbA}_{1 \mathrm{c}}$. We used a multi-centred cohort of the Japan Diabetes Complications Study (JDCS) with 8 years of follow up.

\section{Methods}

This study is a part of the JDCS, a Japanese nationwide multi-centred randomised trial of 2,033 adults (1,087 men and 946 women) with type 2 diabetes aged between 40 and 70 years. Details of study design have been described elsewhere [20, 21]. Baseline characteristics of the study participants are shown in Table 1. In brief, study participants were invited to participate if they had an $\mathrm{HbA}_{1 \mathrm{c}}$ level of more than $6.5 \%(47.5 \mathrm{mmol} / \mathrm{mol})$ and were aged 40 70 years; patients with impaired glucose tolerance were excluded. As a result, the $\mathrm{HbA}_{1 \mathrm{c}}$ level of study patients ranged between $6.0 \%(42.1 \mathrm{mmol} / \mathrm{mol})$ and $15.8 \%$ (149.2 mmol/mol). Those who have major ocular disease (e.g. glaucoma, dense cataract or history of cataract surgery) were excluded from the current analysis. Participants were randomly assigned to a lifestyle intervention or conventional treatment and followed up annually from March 1996 until March 2003. We analysed follow-up data until March 2003. The study was approved by the committee of the Ministry of Health, Labour and Welfare, Japan. We obtained written informed consent from all patients. As we reported in our previous paper, there was no significant difference in incidence or progression of diabetic retinopathy between the control group and the intervention group (aHR for incidence or progression of 
Table 1 Baseline clinical characteristics of type 2 diabetes patients in the Japan Diabetes Complications Study
Data are percentages or mean \pm SD except for: ${ }^{a}$ median (IQR)

\begin{tabular}{|c|c|c|}
\hline Characteristic & $\begin{array}{l}\text { Incidence of diabetic } \\
\text { retinopathy }(n=1,221)\end{array}$ & $\begin{array}{l}\text { Progression of diabetic } \\
\text { retinopathy }(n=410)\end{array}$ \\
\hline Sex (female \%) & 45.0 & 49.5 \\
\hline Age (years) & $58.2 \pm 6.9$ & $59.1 \pm 6.9$ \\
\hline Diabetes duration (years) & $9.8 \pm 6.8$ & $12.8 \pm 7.1$ \\
\hline$<5$ years $(\%)$ & 26.2 & 11.5 \\
\hline $5-10$ years $(\%)$ & 33.6 & 27.6 \\
\hline$\geq 10$ years $(\%)$ & 40.2 & 60.9 \\
\hline BMI $\left(\mathrm{kg} / \mathrm{m}^{2}\right)$ & $23.1 \pm 3.1$ & $23.1 \pm 3.0$ \\
\hline Systolic blood pressure (mmHg) & $130.9 \pm 16.1$ & $132.8 \pm 16.3$ \\
\hline Diastolic blood pressure $(\mathrm{mmHg})$ & $77.2 \pm 10.0$ & $76.3 \pm 9.4$ \\
\hline Fasting plasma glucose $^{\mathrm{a}}(\mathrm{mmol} / \mathrm{l})$ & $8.4(7.3-9.9)$ & $8.5(7.3-9.9)$ \\
\hline $\mathrm{HbA}_{1 \mathrm{c}}$ at baseline $(\%)$ & $7.8 \pm 1.3$ & $8.0 \pm 1.2$ \\
\hline $\mathrm{HbA}_{1 \mathrm{c}}$ at baseline $(\mathrm{mmol} / \mathrm{mol})$ & $61.7 \pm 14.2$ & $63.9 \pm 13.1$ \\
\hline$<7.0 \%(<53.0 \mathrm{mmol} / \mathrm{mol})(\%)$ & 27.2 & 21.5 \\
\hline 7.0 to $<9.0 \%(53.0$ to $<74.9 \mathrm{mmol} / \mathrm{mol})(\%)$ & 59.4 & 57.8 \\
\hline$\geq 9.0 \%(\geq 74.9 \mathrm{mmol} / \mathrm{mol})(\%)$ & 13.4 & 20.7 \\
\hline Total cholesterol (mmol/l) & $5.2 \pm 0.9$ & $5.1 \pm 0.8$ \\
\hline LDL-cholesterol (mmol/l) & $3.2 \pm 0.8$ & $3.1 \pm 0.8$ \\
\hline Triacylglycerol $^{\mathrm{a}}(\mathrm{mmol} / \mathrm{l})$ & $1.2(0.6-1.7)$ & $1.1(0.6-1.7)$ \\
\hline HDL-cholesterol (mmol/l) & $1.4 \pm 0.5$ & $1.5 \pm 0.4$ \\
\hline Exercise $(\mathrm{kJ} / \text { day })^{\mathrm{a}}$ & $602.1(129.3-1,243.1)$ & $498.3(96.2-1,259.0)$ \\
\hline \multicolumn{3}{|l|}{ Therapy components } \\
\hline \multicolumn{3}{|l|}{ Diabetes } \\
\hline Diet only $(\%)$ & 24.2 & 10.0 \\
\hline Insulin $(\%)$ & 14.0 & 27.1 \\
\hline Sulfonylureas (\%) & 56.1 & 64.3 \\
\hline$\alpha$-Glucosidase inhibitors $(\%)$ & 16.8 & 22.0 \\
\hline Biguanides (\%) & 4.7 & 6.5 \\
\hline Insulin sensitisers (\%) & 1.8 & 1.5 \\
\hline Antihypertensive agents (\%) & 25.0 & 26.8 \\
\hline Agents for hyperlipidaemia (\%) & 24.4 & 26.1 \\
\hline \multicolumn{3}{|l|}{ Smoking status } \\
\hline Current smoker (\%) & 29.7 & 23.9 \\
\hline Past smoker $(\%)$ & 24.4 & 22.9 \\
\hline Never smoked (\%) & 46.0 & 53.2 \\
\hline \multicolumn{3}{|l|}{ Alcohol intake } \\
\hline 0 g/day $(\%)$ & 61.3 & 63.3 \\
\hline $1-37$ g/day $(\%)$ & 30.9 & 31.2 \\
\hline$\geq 38$ g/day $(\%)$ & 7.8 & 5.4 \\
\hline
\end{tabular}

diabetic retinopathy compared with the control arm: 0.82 [95\% CI 0.65-1.02] and 0.76 [95\% CI $0.45-1.22$ ], respectively) [21].

Assessment of diabetic retinopathy Presence and severity of diabetic retinopathy was determined annually by local ophthalmologists at each study site and history of ocular surgery was also surveyed. Following the international diabetic retinopathy and diabetic macular oedema disease scales [22], severity of diabetic retinopathy was categorised into five stages of 'no retinopathy', 'mild non-proliferative diabetic retinopathy', 'moderate non-proliferative diabetic retinopathy', 'severe non-proliferative diabetic retinopathy', and 'proliferative diabetic retinopathy'. To validate the consistency of grading between study sites, we crossexamined fundus images and evaluated the agreement in grading between local ophthalmologists and retinal specialists (RK and HY). The estimate of kappa statistics for the 
agreement was 0.56 (95\% CI $0.52-0.59)$ and was considered to be above moderate.

Definition of incidence and progression of diabetic retinopathy 'Incidence of diabetic retinopathy' was defined as having no diabetic retinopathy signs in either eye at baseline and having mild to severe non-proliferative diabetic retinopathy or proliferative diabetic retinopathy in either of the eyes at two consecutive follow-up years. 'Progression of diabetic retinopathy' was defined as having mild non-proliferative diabetic retinopathy at baseline, and having severe nonproliferative diabetic retinopathy, proliferative diabetic retinopathy, or laser photocoagulation treatment for diabetic retinopathy at follow-up at two consecutive follow-up years.

Statistical analysis The primary endpoint was 'time-toincidence' or 'time-to-progression' of diabetic retinopathy. The time from baseline registration was calculated for each participant from the starting point to the date of incidence of diabetic retinopathy, or progression of diabetic retinopathy. In addition to the events of incidence or progression of diabetic retinopathy, cataract surgery and death were considered as censoring. We used the Kaplan-Meier method to plot the cumulative proportion of incidence or progression of diabetic retinopathy. We reported crude and multivariate-adjusted hazards ratios (aHRs) using the Cox proportional hazard models. In the multivariate model, covariates were selected by the backward selection method at $p>0.1$ from the following variables: age, sex, duration of diabetes, age at diagnosis of diabetes, life style intervention, BMI, waist circumference, systolic blood pressure, diastolic blood pressure, $\mathrm{HbA}_{1 \mathrm{c}}$ at baseline, HDL-cholesterol, LDL-cholesterol, triacylglycerol, smoking (current vs non-current smoker), alcohol consumption ( $\geq 38 \mathrm{~g} /$ day vs $1-37 \mathrm{~g} /$ day vs $0 \mathrm{~g} /$ day) and intervention (vs control). We also examined associations between diabetic retinopathy and $\mathrm{HbA}_{1 \mathrm{c}}$ using time-dependent Cox regression analysis, which incorporates all measurements of $\mathrm{HbA}_{1 \mathrm{c}}$ during follow up as one time-dependent covariate. To explore whether there is any dynamic change in risk associations, such as a rapid increase in risk of incident diabetic retinopathy, we used multivariate-adjusted general- ised additive models with a spline function of three degrees of freedom including diabetes duration, BMI, systolic blood pressure and $\mathrm{HbA}_{1 \mathrm{c}}$ as covariates. All $p$ values are two-sided and $p<0.05$ was considered statistically significant. Statistical analyses were carried out using the SAS software package (version 9.2; SAS Institute, Cary, NC, USA).

\section{Results}

Baseline characteristics of people at risk of incidence or progression of diabetic retinopathy are shown in Table 1. The baseline $\mathrm{HbA}_{1 \mathrm{c}}$ level for the entire study sample was $7.8 \pm 1.3 \%(61.7 \pm 14.2 \mathrm{mmol} / \mathrm{mol}$ ) (range $6.0-15.8 \%$ [42.1-149.2 $\mathrm{mmol} / \mathrm{mol}])$. There were 1,221 patients who had no diabetic retinopathy at baseline and were at risk of incident diabetic retinopathy; there were 325 cumulative incident cases of diabetic retinopathy (risk in 8 year period 26.6\%; annual risk 3.3\%), and the incidence rate was 38.3/1,000 person-years. There were 410 patients who had mild non-proliferative diabetic retinopathy at baseline and were at risk of progression of diabetic retinopathy; there were 65 cumulative cases with a progression of diabetic retinopathy (risk in 8 year period $15.9 \%$; annual risk $2.0 \%$ ), and the progression rate was 21.1/1,000 person-years.

Using the stepwise backward variable selection method, duration of diabetes (aHR 1.26 [95\% CI 1.17-1.35] per +5 years, $p<0.0001)$, higher BMI (aHR $1.05[95 \% \mathrm{CI}$ 1.00-1.09] per $\left.+1 \mathrm{~kg} / \mathrm{m}^{2}, p=0.019\right)$, higher systolic blood pressure (aHR 1.09 [95\% CI 1.02-1.17] per $+10 \mathrm{mmHg}$, $p=0.014)$ and higher $\mathrm{HbA}_{1 \mathrm{c}}(\mathrm{aHR} 1.36$ [95\% CI 1.28-1.45] per $+1 \%$ [10.9 mmol $/ \mathrm{mol}], p<0.0001)$, were selected as significant characteristics associated with incidence of diabetic retinopathy (Table 2). In contrast, higher $\mathrm{HbA}_{1 \mathrm{c}}$ was the only characteristic selected as significantly associated with progression of diabetic retinopathy (aHR per $+1 \%$ [10.9 mmol $/ \mathrm{mol}] 1.66$ [95\% CI 1.41-1.95], $p<0.0001)$ (Table 2).

These associations between $\mathrm{HbA}_{1 \mathrm{c}}$ and incidence or progression of diabetic retinopathy remained consistent

Table 2 Associations between incidence or progression of diabetic retinopathy and risk factors selected by the stepwise backward procedure in multivariate Cox regression models

\begin{tabular}{|c|c|c|c|c|c|c|}
\hline \multirow[t]{2}{*}{ Variable } & \multicolumn{3}{|c|}{ Incidence of diabetic retinopathy $(n=1,221)$} & \multicolumn{3}{|c|}{ Progression of diabetic retinopathy $(n=410)$} \\
\hline & aHR & $95 \% \mathrm{CI}$ & $p$ value & aHR & $95 \% \mathrm{CI}$ & $p$ value \\
\hline Diabetes duration (per 5 year period) & 1.26 & $(1.17-1.35)$ & $<0.0001$ & - & - & - \\
\hline BMI (per $\left.1 \mathrm{~kg} / \mathrm{m}^{2}\right)$ & 1.05 & $(1.00-1.09)$ & 0.019 & - & - & - \\
\hline Systolic blood pressure (per $10 \mathrm{mmHg}$ ) & 1.09 & $(1.02-1.17)$ & 0.014 & - & - & - \\
\hline $\mathrm{HbA}_{1 \mathrm{c}}($ per $1 \%[10.9 \mathrm{mmol} / \mathrm{mol}])$ & 1.36 & $(1.28-1.45)$ & $<0.0001$ & 1.66 & $(1.41-1.95)$ & $<0.0001$ \\
\hline
\end{tabular}


when we used $\mathrm{HbA}_{1 \mathrm{c}}$ level as a time-dependent covariate accounting for change in $\mathrm{HbA}_{1 \mathrm{c}}$ during the follow-up period (aHRs for incidence or progression of diabetic retinopathy per $+1 \%[10.9 \mathrm{mmol} / \mathrm{mol}]$ change in $\mathrm{HbA}_{1 \mathrm{c}}$ : 1.36 [95\% CI 1.27-1.47], $p<0.0001$ and 1.33 [95\% CI $1.11-1.60], p=0.001$, respectively).

When we replaced duration of diabetes with age at diagnosis of diabetes ( $\geq 50$ years old vs $<50$ years old) in the multivariate model, individuals who were diagnosed with diabetes at $\geq 50$ years old were significantly less likely to develop diabetic retinopathy compared with individuals who were diagnosed at $<50$ years old (aHR 0.72 [95\% CI $0.57-0.90], p=0.004$ ).

Figure 1a,b show the Kaplan-Meier plot for the incidence and progression of diabetic retinopathy by three levels of $\mathrm{HbA}_{1 \mathrm{c}}$. Compared with patients with $\mathrm{HbA}_{1 \mathrm{c}}<7.0 \%(53.0 \mathrm{mmol} / \mathrm{mol})$, individuals with $7.0 \%$ $(53.0 \mathrm{mmol} / \mathrm{mol}) \leq \mathrm{HbA}_{1 \mathrm{c}}<9.0 \%(74.9 \mathrm{mmol} / \mathrm{mol})$ and individuals with $\mathrm{HbA}_{1 \mathrm{c}} \geq 9.0 \%(74.9 \mathrm{mmol} / \mathrm{mol})$ had significantly higher risk of incident diabetic retinopathy (HR 1.98 [95\% CI 1.44-2.70], $p<0.0001$, and 4.04 [95\% CI 2.83-5.78], $p<0.0001$, respectively). Patients with $\mathrm{HbA}_{1 \mathrm{c}} \geq 9.0 \%(74.9 \mathrm{mmol} / \mathrm{mol})$ had an eightfold higher risk of progression of diabetic retinopathy compared with that in the patients with $\mathrm{HbA}_{1 \mathrm{c}}<7.0 \%(53.0 \mathrm{mmol} / \mathrm{mol})$ (HR7.92, 95\% CI 3.08-20.36, $p<0.0001$ ).

Association between risk over an 8 year period of the incidence of diabetic retinopathy and $\mathrm{HbA}_{1 \mathrm{c}}$ (Fig. 2a) or diabetes duration (Fig. 2b) were estimated using generalised additive models. As shown, there was no indication of the presence of a threshold in associations between $\mathrm{HbA}_{1 \mathrm{c}}$ and risk of incidence of diabetic retinopathy. In contrast, as shown in Fig. 2b, there was a dynamic increase in the risk of developing diabetic retinopathy between 5 years and 10 years of duration of diabetes. In general, the risk of incidence of diabetic retinopathy increases with longer duration of diabetes; it increases more rapidly between 5 years $(0.185,95 \%$ CI $0.149-0.227)$ and 10 years $(0.313$, 95\% CI $0.263-0.368)$. The risk of incidence of diabetic retinopathy is more stable with $<5$ years or $\geq 10$ years of duration of diabetes.

\section{Discussion}

Using the JDCS cohort, we reported the incidence rate of diabetic retinopathy in Japanese adult type 2 diabetes patients with a long-term follow up of 8 years. The observed incident rate $(38.3 / 1,000$ person-years) was close to the previous reports of incident rate of diabetic retinopathy from Asian populations [13, 14].

Strengths of our study are that it involved a multicentred study design covering a large geographical area in
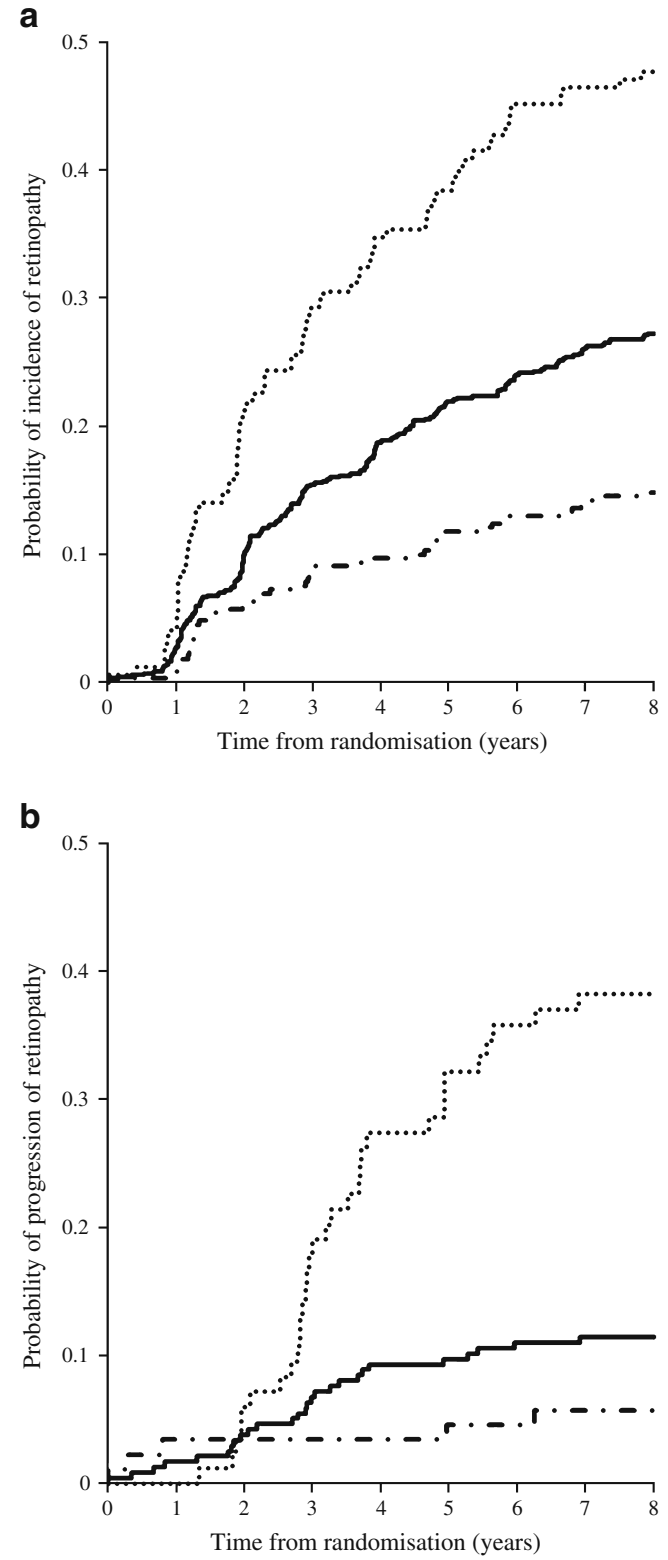

Fig. 1 a Kaplan-Meier plot for the incidence of retinopathy by $\mathrm{HbA}_{1 \mathrm{c}}$ level (dotted line, $\mathrm{HbA}_{1 \mathrm{c}} \geq 9.0 \%$; black line, 9.0\%> $\mathrm{HbA}_{1 \mathrm{c}} \geq$ $7.0 \%$; dashed line, $\mathrm{HbA}_{1 \mathrm{c}}<7.0 \%$ ). b Kaplan-Meier plot for the progression of retinopathy by $\mathrm{HbA}_{1 \mathrm{c}}$ level (dotted line, $\mathrm{HbA}_{1 \mathrm{c}} \geq 9.0 \%$; black line, $9.0 \%>\mathrm{HbA}_{1 \mathrm{c}} \geq 7.0 \%$; dashed line, $\mathrm{HbA}_{1 \mathrm{c}}<7.0 \%$ ) $\left(\mathrm{HbA}_{1 \mathrm{c}} 7 \%\right.$ is equivalent to $53.0 \mathrm{mmol} / \mathrm{mol} ; 9 \%$ is equivalent to $74.9 \mathrm{mmol} / \mathrm{mol}$ )

Japan, and a large sample size of $>1,000$. Limitations might include the accuracy of diabetic retinopathy grading based on clinical diagnosis, when compared with grading based on seven-field stereo fundus photography. Although we validated the consistency of grading as moderate compared with photographic grading in a sub-sample, subtle diabetic retinopathy change can be overlooked and the outcomes of incidence or progression of diabetic retinopathy can be underestimated. Selection bias by 
a

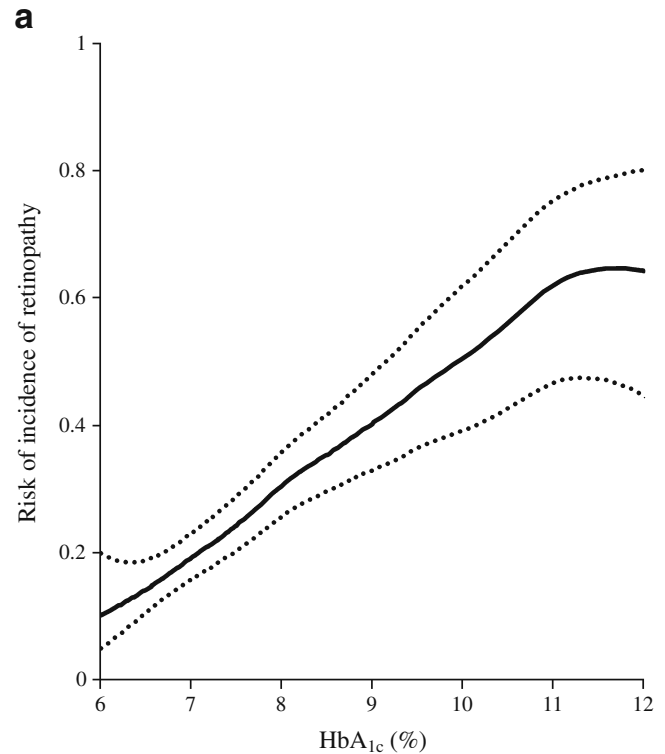

b

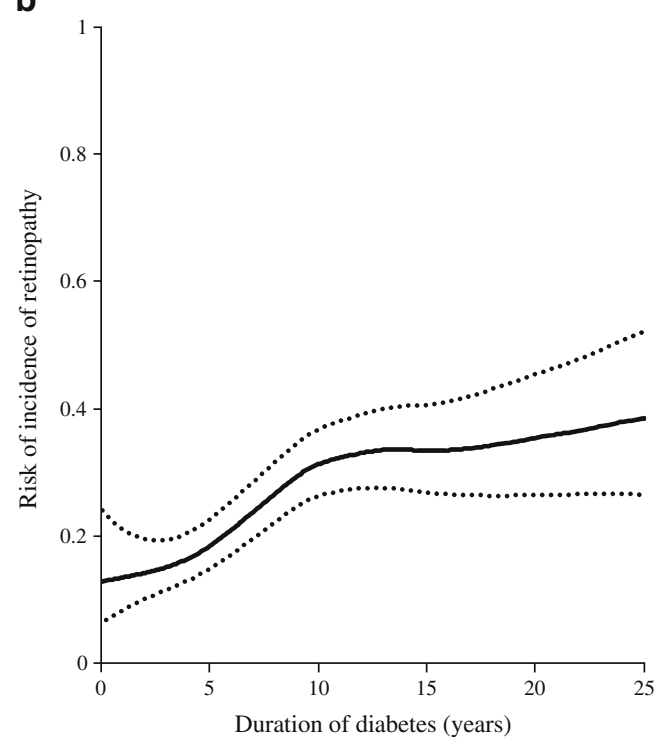

Fig. 2 a Risk (black line) and 95\% CI (dotted lines) of the incidence of retinopathy in relation to $\mathrm{HbA}_{1 \mathrm{c}}$ estimated by generalised additive models. b Risk (black line) and 95\% CI (dotted lines) of the incidence of retinopathy in relation to diabetes duration estimated by generalised additive models

including patients for lifestyle intervention might overestimate the incidence and progression of diabetic retinopathy than in the diabetic population in general.

The incidence rate of diabetic retinopathy in this study was comparable to previous studies from Asian populations. Kim et al. [13] reported the incidence rate of diabetic retinopathy in Korean type 2 diabetic patients as 44.4/1,000 person-years over a follow-up of 5.3 years; Sasaki et al. [14] reported the incidence rate of diabetic retinopathy as $39.8 / 1,000$ person-years in Japanese type 2 diabetes patients ( $n=976$; follow-up of 8.3 years). The observed incident rate in this study was slightly lower than that reported in white or Hispanic populations in western countries $(3.3 \%$ in this study vs $4.4-8.6 \%)$ [10, 23, 24].

With regard to risk associations, $\mathrm{HbA}_{1 \mathrm{c}}$ (either at baseline or change over time) was the most relevant risk factor for both incidence and progression of diabetic retinopathy. Risk of incidence and progression of diabetic retinopathy increased linearly by $36 \%$ and $66 \%$ for every $1 \%$ [ $10.9 \mathrm{mmol} / \mathrm{mol}]$ increase in $\mathrm{HbA}_{1 \mathrm{c}}$ at baseline, respectively. This association was consistently found when we treat $\mathrm{HbA}_{1 \mathrm{c}}$ level as a time-dependent variable accounting for change in $\mathrm{HbA}_{1 \mathrm{c}}$ over follow-up time. We also found that here were no suggestions of a threshold effect in $\mathrm{HbA}_{1 \mathrm{c}}$ level, which would rapidly increase the risk of incidence or progression of diabetic retinopathy; the association between $\mathrm{HbA}_{1 \mathrm{c}}$ level and incidence or progression of diabetic retinopathy seems to be linear (Fig. 2a). One limitation of our study is that individuals involved in this study have an $\mathrm{HbA}_{1 \mathrm{c}}$ range of $6.0 \%(42.1 \mathrm{mmol} / \mathrm{mol})$ to $15.8 \%(149.2 \mathrm{mmol} / \mathrm{mol})$, and we cannot confirm whether there is a threshold effect outside this range. This warrants further study to determine the therapeutic target with a cut-off $\mathrm{HbA}_{1 \mathrm{c}}$ value for reducing risk of incidence or progression of diabetic retinopathy. We have also observed that individuals who were diagnosed at $\geq 50$ years old were significantly less likely to develop diabetic retinopathy compared with individuals who were diagnosed at $<50$ years old; association of $\mathrm{HbA}_{1 \mathrm{c}}$ and incidence or progression of diabetic retinopathy did not change significantly even adjusting for age at onset.

An association between longer duration of diabetes and incidence of diabetic retinopathy was also confirmed in this study. With regard to the duration of diabetes, the risk of incidence of diabetic retinopathy increases rapidly from 5 years to 10 years duration while the change in risk was stable at $<5$ years or $\geq 10$ years of duration (Fig. 2b). Although the duration of diabetes is not a modifiable risk characteristic, our findings might contribute to better management strategies by suggesting that patients with 5-10 years of duration of diabetes may have greater risk of developing diabetic retinopathy and thus need more intensive follow up compared with those with $\geq 10$ years of duration of diabetes.

We found an association between higher BMI and incidence of diabetic retinopathy. While it is still controversial, obesity has been shown to be associated with increased risk of incident diabetic retinopathy [1]. In our earlier analysis, we have reported a significant difference in BMI in persons with type 2 diabetes between western and Japanese populations [25]; BMI in Japanese patients with type 2 diabetes was significantly lower than that in western populations [25]. In this study, we found that higher BMI is significantly associated with the incidence of diabetic 
retinopathy even within the relatively lower BMI range $\left(23.1 \pm 3.0 \mathrm{~kg} / \mathrm{m}^{2}\right)$. This finding warrants further research to assess whether Asian individuals who are overweight are also at risk of developing diabetic retinopathy.

In conclusion, we have reported the incidence rate and progression rate of diabetic retinopathy in adult Japanese patients with type 2 diabetes over 8 years. We found that higher $\mathrm{HbA}_{1 \mathrm{c}}$ level was significantly and linearly associated with both incidence and progression of diabetic retinopathy. Higher BMI and higher systolic blood pressure were also associated with higher risk of developing diabetic retinopathy. Duration of diabetes was also associated with increasing risk of incidence of diabetic retinopathy; the risk of incidence of diabetic retinopathy increases rapidly between 5 and 10 years. This study emphasises the importance of glycaemic control in the management of diabetic retinopathy in Asian patients with type 2 diabetes.

Acknowledgements We thank many diabetologists and patients at 59 participating institutes throughout Japan. This study is financially supported by the Ministry of Health, Labour and Welfare, Japan. The sponsor had no role in the design and conduct of the study.

Duality of interest The authors declare that there is no duality of interest associated with this manuscript.

\section{References}

1. Mohamed Q, Gillies MC, Wong TY (2007) Management of diabetic retinopathy: a systematic review. JAMA 298:902-916

2. Vallance JH, Wilson PJ, Leese GP, McAlpine R, MacEwen CJ, Ellis JD (2008) Diabetic retinopathy: more patients, less laser: a longitudinal population-based study in Tayside, Scotland. Diabetes Care 31:1126-1131

3. Misra A, Bachmann MO, Greenwood RH et al (2009) Trends in yield and effects of screening intervals during 17 years of a large UK community-based diabetic retinopathy screening programme. Diabet Med 26:1040-1047

4. Wong TY, Mwamburi M, Klein R et al (2009) Rates of progression in diabetic retinopathy during different time periods: a systematic review and meta-analysis. Diabetes Care 32:23072313

5. Wild S, Roglic G, Green A, Sicree R, King H (2004) Global prevalence of diabetes: estimates for the year 2000 and projections for 2030. Diabetes Care 27:1047-1053

6. Zimmet P, Alberti KG, Shaw J (2001) Global and societal implications of the diabetes epidemic. Nature 414:782-787

7. International Diabetes Federation (2009) IDF Diabetes Atlas 2009. In: Federation ID (ed) International Diabetes Federation, Brussels, Belgium

8. Klein R, Knudtson MD, Lee KE, Gangnon R, Klein BE (2008) The Wisconsin Epidemiologic Study of Diabetic Retinopathy: XXII the twenty-five-year progression of retinopathy in persons with type 1 diabetes. Ophthalmology 115:1859-1868
9. Grauslund J, Green A, Sjolie AK (2009) Prevalence and 25 year incidence of proliferative retinopathy among Danish type 1 diabetic patients. Diabetologia 52:1829-1835

10. Varma R, Choudhury F, Klein R et al (2010) Four-year incidence and progression of diabetic retinopathy and macular edema: the Los Angeles Latino Eye Study. Am J Ophthalmol 149:752-761

11. Chen MS, Kao CS, Fu CC, Chen CJ, Tai TY (1995) Incidence and progression of diabetic retinopathy among non-insulin-dependent diabetic subjects: a 4-year follow-up. Int J Epidemiol 24:787-795

12. Janghorbani M, Amini M, Ghanbari H, Safaiee H (2003) Incidence of and risk factors for diabetic retinopathy in Isfahan, Iran. Ophthalmic Epidemiol 10:81-95

13. Kim HK, Kim CH, Kim SW et al (1998) Development and progression of diabetic retinopathy in Koreans with NIDDM. Diabetes Care 21:134-138

14. Sasaki A, Horiuchi N, Hasewgawa K, Uehara M (1990) Development of diabetic retinopathy and its associated risk factors in type 2 diabetic patients in Osaka district, Japan: a long-term prospective study. Diabetes Res Clin Pract 10:257-263

15. Klein R, Klein BE, Moss SE, Davis MD, DeMets DL (1984) The Wisconsin Epidemiologic Study of Diabetic Retinopathy. III. Prevalence and risk of diabetic retinopathy when age at diagnosis is 30 or more years. Arch Ophthalmol 102:527-532

16. Okudaira M, Yokoyama H, Otani T, Uchigata Y, Iwamoto Y (2000) Slightly elevated blood pressure as well as poor metabolic control are risk factors for the progression of retinopathy in earlyonset Japanese type 2 diabetes. J Diabetes Complications 14:281287

17. Shiraiwa T, Kaneto H, Miyatsuka T et al (2005) Post-prandial hyperglycemia is an important predictor of the incidence of diabetic microangiopathy in Japanese type 2 diabetic patients. Biochem Biophys Res Commun 336:339-345

18. Shiraiwa T, Kaneto H, Miyatsuka T et al (2005) Postprandial hyperglycemia is a better predictor of the progression of diabetic retinopathy than $\mathrm{HbA}_{1 \mathrm{c}}$ in Japanese type 2 diabetic patients. Diabetes Care 28:2806-2807

19. American Diabetes Association (2010) Standards of medical care in diabetes. Diabetes Care 33(Suppl 1):S11-S61

20. Sone H, Katagiri A, Ishibashi S et al (2002) Effects of lifestyle modifications on patients with type 2 diabetes: the Japan Diabetes Complications Study (JDCS) study design, baseline analysis and three year-interim report. Horm Metab Res 34:509-515

21. Sone H, Tanaka S, Iimuro S et al (2010) Long-term lifestyle intervention lowers the incidence of stroke in Japanese patients with type 2 diabetes: a nationwide multicentre randomised controlled trial (the Japan Diabetes Complications Study). Diabetologia 53:419-428

22. Wilkinson CP, Ferris FL 3rd, Klein RE et al (2003) Proposed international clinical diabetic retinopathy and diabetic macular edema disease severity scales. Ophthalmology 110:1677-1682

23. Klein R, Klein BE, Moss SE, Cruickshanks KJ (1998) The Wisconsin Epidemiologic Study of Diabetic Retinopathy: XVII. The 14-year incidence and progression of diabetic retinopathy and associated risk factors in type 1 diabetes. Ophthalmology 105:1801-1815

24. Cikamatana L, Mitchell P, Rochtchina E, Foran S, Wang JJ (2007) Five-year incidence and progression of diabetic retinopathy in a defined older population: the Blue Mountains Eye Study. Eye (Lond) 21:465-471

25. Sone H, Ito H, Ohashi Y, Akanuma Y, Yamada N (2003) Obesity and type 2 diabetes in Japanese patients. Lancet 361:85 